\title{
Integração de critérios técnicos, ambientais e sociais em estudos de alternativas locacionais para implantação de aterro sanitário
}

\section{Integrating technical, environmental and social criteria in landfill sitting studies}

\author{
Marcelo Montaño \\ Engenheiro Mecânico. Professor do Departamento de Hidráulica e Saneamento da Escola de Engenharia de São Carlos da Universidade de São Paulo (USP) - \\ São Carlos (SP), Brasil.

\section{Victor Eduardo Lima Ranieri} \\ Engenheiro Agrônomo. Professor do Departamento de Hidráulica e Saneamento da Escola de Engenharia de São Carlos da Universidade de São Paulo (USP) - \\ São Carlos (SP), Brasil.
}

\section{Valdir Schalch}

Engenheiro Químico. Professor do Departamento de Hidráulica e Saneamento da Escola de Engenharia de São Carlos da Universidade de São Paulo (USP) São Carlos (SP), Brasil.

\section{Aurélio Teodoro Fontes}

Engenheiro Civil. Pesquisador do Núcleo de Ciências e Política Ambiental da Faculdade de Filosofia, Ciências e Letras de Ribeirão Preto da Universidade de São Paulo (USP) - Ribeirão Preto (SP), Brasil.

\section{Marcus César Avezum Alves de Castro}

Engenheiro Mecânico. Professor do Departamento de Geociências da Universidade Estadual Paulista Júlio de Mesquita Filho (UNESP) - Rio Claro (SP), Brasil.

\section{Marcelo Pereira de Souza}

Engenheiro Civil. Professor do Departamento de Biologia da Faculdade de Filosofia, Ciências e Letras de Ribeirão Preto da Universidade de São Paulo (USP) Ribeirão Preto (SP), Brasil.

\section{Resumo}

A Política Nacional do Meio Ambiente tem como objetivo a conciliação do desenvolvimento econômico e social com a qualidade ambiental, e dispõe de vários instrumentos que procuram contemplara capacidade de suporte do meio. Assim, a discussão sobre a localização das atividades é uma etapa importante para a avaliação da viabilidade ambiental de um determinado empreendimento, notadamente em processos de licenciamento ambiental. O trabalho apresenta uma abordagem metodológica para integração de critérios técnicos, ambientais e sociais em estudos de alternativas de localização de aterros sanitários, com especial atenção à interação entre os aspectos ambientais e os elementos fundamentais de um projeto (a saber, requisitos locacionais e concepção tecnológica), aplicado em um estudo de caso em São Carlos (SP). Como resultados principais, destacam-se o maior foco nos impactos significativos e a possibilidade de envolvimento de segmentos importantes da sociedade previamente à elaboração dos estudos ambientais.

Palavras-chave: alternativas locacionais; avaliação de impacto ambiental; licenciamento ambiental; capacidade de suporte; aterro sanitário.

\begin{abstract}
The National Environment Policy aims to reconcile economic and social development with environmental quality and has several instruments to address environmental issues within the decision making processes. Thus, the discussion about the location of activities is an important step in the evaluation of the environmental acceptability of aparticular activity, even though the systematic procedures do not require neither to the entrepreneur or to the government studies of sitting alternatives. This paper presents the integration of technical, environmental and social criteria in a landfill sitting study, in order to present a systematic integration of environmental factors and applies in a case study in São Carlos, Brazil. The results allowed the development of an environmental impact statement more focused on significant impacts and the participation of segments of society at early stages of project's development.
\end{abstract}

Keywords: locational alternatives; environmental impact assessment; environmental licensing; carrying capacity; landfill. 


\section{Introdução}

O objetivo da Política Nacional do Meio Ambiente (PNMA) instituída pela Lei no 6.938 de 1981, é a conciliação do desenvolvimento econômico e social com a qualidade ambiental. Trata-se, portanto, de uma abordagem tecnocentrista acomodativa (OLIVEIRA; MONTAÑO; SOUZA, 2009; VAN BELLEN, 2007; PEARCE; TURNER, 1991) e que pauta a atuação dos diversos integrantes do Sistema Nacional do Meio Ambiente (SISNAMA), nos diferentes entes da Federação e seus respectivos níveis de competência.

Para a consecução desses objetivos, a PNMA instituiu seus instrumentos, cuja aplicabilidade é vinculada à produção e disponibilização de informações (sociais, econômicas e ambientais) para a tomada de decisão. Para tanto, a implementação dos instrumentos observa requisitos como tempo (as informações devem estar disponíveis no momento em que são requisitadas, possibilitando sua inclusão em cada etapa do processo decisório) e escala (em nível de detalhamento compatível com a decisão a ser tomada).

Cabe observar que as indicações sobre a capacidade do território em suportar os impactos causados pelas atividades humanassão essenciais para que o aspecto econômico não seja ponderado de maneira isolada no processo decisório e, posteriormente, condicione a incorporação dos fatores sociais e ambientais. Assim, a capacidade de suporte, também, é base para as decisões com compromisso ambiental, de estudos de localização e para a determinação da viabilidade ambiental de empreendimentos, (MCHARG, 1969; RYDIN, 1998; SOUZA, 2000, OLIVEIRA; MONTAÑO; SOUZA, 2009; THERIVEL, 2010).

Ratificando esse entendimento, a legislação aplicada à Avaliação de Impacto Ambiental (CONAMA 01/86 e resoluções correlatas) especifica que sejam consideradas todas as alternativas de localização do projeto. No caso de um aterro sanitário, por exemplo, o atendimento a essa determinação legal significa - idealmente - avaliar todo o território disponível (o município, como regra, mas também da bacia hidrográfica ou região de interesse econômico) quanto à existência de sítios aptos a acomodar tal atividade. Assim, a identificação das alternativas locacionais que apresentem condições adequadas (em termos ambientais) para a implantação do empreendimento é condição essencial ao escopo de um Estudo Prévio de Impacto Ambiental. Tais alternativas compõem, juntamente com as alternativas tecnológicas (relacionadas à concepção do empreendimento), o conjunto de elementos fundamentais para a determinação da viabilidade ambiental do empreendimento ou atividade em questão - objeto específico de análise pelo órgão ambiental, vinculada à solicitação da Licença Prévia.

O presente trabalho trata do estabelecimento de critérios para o estudo de localização de atividades, em específico de aterros sanitários. Valendo-se de uma abordagem metodológica de aproximações sucessivas com integração de critérios técnicos (com atenção ao empreendimento), ambientais (fatores ambientais) e sociais (vizinhança e atores sociais), o trabalho apresenta e discute o caso do aterro sanitário do município de São Carlos (SP).

\section{Critérios para a localização de aterros sanitários}

Os estudos para localização de aterros sanitários têm se concentrado essencialmente em aspectos técnicos, quando comparados aos demais fatores (sociais e ambientais) que compõem o quadro decisório em torno das aprovações necessárias para a implantação de um determinado empreendimento, conforme ilustram Dörhöfer e Siebert (1998), Dorn e Tantiwanit (2001), Frempong (1999) e Hartman e Goltz (2002).

A experiência acumulada em torno dos estudos de localização de atividades permite identificar ao menos duas grandes abordagens para tratar da localização de aterros sanitários, diferenciadas pelo teor dos elementos considerados essenciais aos estudos:

a) Abordagem de natureza técnico-operacional, que se vale de critérios relacionados ao desempenho operacional do empreendimento no que diz respeito ao cumprimento de requisitos legais (exigências dos órgãos de meio ambiente, normas específicas, etc.) e econômicos (distância ao centro gerador, custo para a desapropriação da área, existência de material para cobertura próximo à área escolhida, etc.);

b) Abordagem de natureza socioambiental que incorpora, em primeiro plano, preocupações relacionadas ao desempenho ambiental do empreendimento, especialmente quanto aos impactos ambientais potenciais (meios físico, biológico e antrópico) relacionados, considerando-se o risco associado às suas diferentes fases (implementação, operação e desativação), sobretudo pela possibilidade de falhas nas medidas de proteção adotadas.

Vale destacar, ainda, a natureza política do processo de seleção de áreas, associada a empreendimentos que podem despertar, por suas características, reações contrárias por parte dos diferentes segmentos sociais e grupos políticos direta ou indiretamente afetados pelo empreendimento.

Zuquette et al. (1994) apresentam uma ponderação aplicada à região de Piracicaba para a seleção de áreas para implantação de aterros sanitários, procurando uma adequação frente às condições brasileiras, que implicam em obtenção de informações em escala regional a local, situada entre 1:100.000 e 1:25.000. Os autores apresentam uma matriz de ponderação com 34 atributos (relacionados aos fatores substrato rochoso, materiais inconsolidados, recursos hídricos, relevo e características climáticas), a serem considerados nos estudos de localização, definindo para cada atributo um intervalo associado ao grau de adequação para a implantação de um aterro sanitário. Basílio (2001) reproduz a aplicação desta metodologia para a seleção de áreas para implantação de aterros sanitários na região de Campinas. 
Aplicados especificamente na região de São Carlos, destacam-se os trabalhos de Muro (2000) - que avalia o território do município, acrescentando à metodologia de Zuquette et al. (1994) uma ponderação sobre a distância às áreas urbanas -, e de Marques (2002) - que propõe modificações na metodologia referida, valendo-se dos mesmos fatores à exceção das características climáticas, aplicando à folha Araraquara (1:50.000). Por sua vez, Pfeiffer (2001) apresenta uma revisão relativa a diferentes critérios empregados para a escolha de áreas para a implantação de aterros sanitários.

Tabela 1 - Critérios para localização de aterros sanitários conforme diferentes autores.

\begin{tabular}{|c|c|c|c|c|c|c|c|c|}
\hline \multirow[b]{2}{*}{ Referências } & \multicolumn{8}{|c|}{ Fatores } \\
\hline & $\begin{array}{c}\text { Geologia } \\
\text { Hidrogeologia }\end{array}$ & $\begin{array}{l}\text { Uso do } \\
\text { solo }\end{array}$ & $\begin{array}{l}\text { Tipo de } \\
\text { solo }\end{array}$ & Relevo & $\begin{array}{l}\text { Recursos } \\
\text { hídricos } \\
\text { superficiais }\end{array}$ & $\begin{array}{l}\text { Acesso à } \\
\text { área }\end{array}$ & $\begin{array}{l}\text { Distância } \\
\text { a núcleos } \\
\text { urbanos }\end{array}$ & Outros \\
\hline ABNT 13.896/97 & & & & & & & & $\begin{array}{l}\text { Vida útil, custos, profundidade } \\
\text { do lençol. }\end{array}$ \\
\hline $\begin{array}{l}\text { Basagaoglu et al. } \\
\text { (1997) }\end{array}$ & & & & & & & & $\begin{array}{l}\text { Distância de poços de água } \\
\text { usados para abastecimento } \\
\text { público; atividade sísmica. }\end{array}$ \\
\hline Basílio (2001) & & & & & & & & $\begin{array}{l}\text { Características climáticas } \\
\text { (pluviosidade, direção dos } \\
\text { ventos, evapotranspiração). }\end{array}$ \\
\hline $\begin{array}{l}\text { Charnpratheep; } \\
\text { Zhou; Garner } \\
\text { (1997) }\end{array}$ & & & & & & & & $\begin{array}{l}\text { Distância de poços de água } \\
\text { de abastecimento público; } \\
\text { sítios arqueológicos; distância } \\
\text { de rodovias. }\end{array}$ \\
\hline Kao; Lin (1996) & & & & & & & & $\begin{array}{l}\text { Custos; distância de áreas } \\
\text { naturais ou históricas. }\end{array}$ \\
\hline $\begin{array}{l}\text { Karthikeyan; } \\
\text { Elliott; Brandt } \\
\text { (1996) }\end{array}$ & & & & & & & & - \\
\hline $\begin{array}{l}\text { Leao; Bishop; } \\
\text { Evans (2001) }\end{array}$ & & & & & & & & $\begin{array}{l}\text { Distância de áreas naturais } \\
\text { protegidas e de rodovias. }\end{array}$ \\
\hline $\begin{array}{l}\text { Mahler; Lima } \\
\text { (2003) }\end{array}$ & & & & & & & & $\begin{array}{l}\text { Distância do centro gerador, } \\
\text { infraestrutura disponível, } \\
\text { restrições legais, custos, } \\
\text { evapotranspiração e } \\
\text { pluviosidade, distância } \\
\text { da fonte de material para } \\
\text { recobrimento. }\end{array}$ \\
\hline Marques (2002) & & & & & & & & - \\
\hline Brasil (2002) & & & & & & & & $\begin{array}{l}\text { Vida útil; distância de } \\
\text { Unidades de Conservação; } \\
\text { distância do centro gerador; } \\
\text { custos; disponibilidade de } \\
\text { solo para impermeabilização; } \\
\text { aceitação pela comunidade. }\end{array}$ \\
\hline Muro (2000) & & & & & & & & $\begin{array}{l}\text { Características climáticas } \\
\text { (pluviosidade, direção dos } \\
\text { ventos, evapotranspiração). }\end{array}$ \\
\hline $\begin{array}{l}\text { Sener, Süzen, } \\
\text { Doyuran (2005) }\end{array}$ & & & & & & & & $\begin{array}{l}\text { Distância de rodovias, } \\
\text { ferrovias, aeroportos, dutos, } \\
\text { linhas de transmissão. }\end{array}$ \\
\hline $\begin{array}{l}\text { Siddiqui, Everett, } \\
\text { Vieux (1996) }\end{array}$ & & & & & & & & $\begin{array}{l}\text { Distância de aeroportos, } \\
\text { residências ou núcleos de } \\
\text { residências e de áreas usadas } \\
\text { por espécies ameaçadas. }\end{array}$ \\
\hline São Paulo (2005) & & & & & & & & $\begin{array}{l}\text { Lençol freático, distância de } \\
\text { habitações isoladas, vida útil, } \\
\text { ventos predominantes. }\end{array}$ \\
\hline Souza (1999) & & & & & & & & $\begin{array}{l}\text { Vida útil da unidade, distância } \\
\text { de rodovias. }\end{array}$ \\
\hline Tsuhako (2004) & & & & & & & & Distância de rodovias. \\
\hline $\begin{array}{l}\text { Zuquette et al. } \\
(1994)\end{array}$ & & & & & & & & $\begin{array}{l}\text { Características climáticas } \\
\text { (pluviosidade, direção dos } \\
\text { ventos, evapotranspiração). }\end{array}$ \\
\hline
\end{tabular}


Além do arcabouço acadêmico, vale destacar a existência de normas técnicas e aspectos legais de âmbito estadual e federal, como elementos relevantes para a definição de critérios para localização de aterros sanitários. Com a intenção de apresentar um panorama sobre os critérios comumente empregados na escolha de áreas para aterros sanitários, a Tabela 1 sintetiza um conjunto de critérios empregados para a localização de aterros sanitários, inclusive normas técnicas, resoluções e legislação pertinentes.

\section{Metodologia}

A partir da revisão da literatura e do quadro teórico conceitual sobre a localização de aterros sanitários elaborado, a aplicação para o caso do município de São Carlos (SP), o estudo de alternativas locacionais adotou uma abordagem metodológica de aproximações sucessivas, diferenciadas conforme o nível de análise e a escala das informações:

a) Primeira aproximação: nível regional e escala municipal;

b) Segunda aproximação: nível municipal e escala local;

c) Terceira aproximação: nível local e escala de empreendimento.

\section{Aplicação dos critérios - primeira aproximação}

A partir de uma avaliação preliminar de impactos, foram identificados os impactos ambientaispotencialmente significativos para os meios físico, biótico e antrópico associados ao empreendimento em questão, levando-se em conta requisitos básicos já estabelecidos para o projeto (vida útil, disposição diária, estimativa do tamanho da área a ser utilizada).

$\mathrm{Na}$ determinação da aptidão do meio para implantação de empreendimentos e desenvolvimento de atividades humanas, deve-se tomar como premissa básica o fato de que as características dos meios físico, biológico e antrópico conferem, para cada parcela de território, maior ou menor potencial para as diferentes tipologias de ocupação. No caso de um aterro sanitário é possível assumir que a combinação de fatores como conformação do relevo, tipos de solos, formações geológicas, recursos hídricos, entre outros, determinam a capacidade (ou aptidão) do meio em acomodar certas atividades humanas de forma que os impactos dessas atividades não ultrapassem os níveis aceitos pela sociedade e/ou impostos pela legislação. Por outro lado, outros fatores como a existência de infraestrutura de transporte ou presença de aglomerados urbanos são encarados como elementos que potencializam ou restringem a aptidão do meio para tais atividades.

Em relação especificamente à identificação de áreas que apresentem capacidade de suporte ambiental para acomodar um aterro sanitário que atenda à demanda por disposição de resíduos, e considerando as características fundamentais em sua implantação e operação, é pertinente admitir que os principais impactos potenciais gerados pela atividade em questão são: a contaminação do solo, subsolo e das águas superficiais, subsuperficiais e subterrâneas; a geração de gases e, consequentemente, de odores; e a possibilidade de intensificação de processos erosivos devido à intensa movimentação de terra.

Mas, além destes, determinados impactos intrínsecos a este tipo de empreendimento, relacionados a aspectos socioeconômicos (desvalorização das terras ao redor da área selecionada, interferências em comunidades rurais por aumento no tráfego de veículos, mobilização de forças antagônicas ao processo de implantação do aterro pelo conhecido efeito NIMBY') também devem ser considerados pelos tomadores de decisão, acompanhando todo o processo decisório.

No caso específico do aterro sanitário de São Carlos, após a realização de discussões públicas com representantes do poder público e sociedade para esclarecimento da metodologia e estabelecimento dos fatores considerados prioritários para o estudo de alternativas locacionais (definidos, inclusive, para diferentes níveis de aproximação), têm-se os elementos orientadores para diferentes níveis de aproximação conforme a Tabela 2.

O primeiro nível de aproximação se configura a partir da aplicação do conjunto de critérios dispostos na Tabela 3.

Importante destacar o fato de que cada critério estabelecido é aplicado em função das condições ambientais que representam, admitindo a necessidade de minimização dos impactos ambientais significativos associados ao empreendimento. De maneira resumida, a configuração verificada no caso do município de São Carlos é a seguinte:

a) tipos de solo: sobre áreas de solo com baixa permeabilidade natural;

b) formações geológicas: risco de contaminação de águas subterrâneas;

c) declividade natural do terreno: áreas de baixa declividade natural;

d) distância a corpos de água superficiais: como medida de segurança, no caso de um eventual deslocamento de águas contaminadas via escoamento superficial ou de subsuperfície, e em atendimento a requisitos legais, estabeleceu-se que o aterro deveria observar uma distância de 300 metros dos corpos de água superficial;

e) fragmentos de vegetação nativa: como medida preventiva, a existência de fragmentos de vegetação nativa significativos torna a implantação do aterro inviável;

f) distância a áreas urbanas/condomínios residenciais rurais: a fim de resguardar os aspectos sanitários e minimizar conflitos entre empreendimento e comunidade, considerou-se inviável implantar o aterro a uma distância inferior a 2.000 metros de áreas 
urbanizadas ou do perímetro urbano, incluindo distritos, condomínios e núcleos rurais;

g) restrições de caráter institucional: por demandarem tratamentos específicos, a fim de viabilizar a implantação do aterro sanitário sobre determinadas áreas, foram indicadas a delimitação da Área de Proteção Ambiental de Corumbataí-Botucatu-Tejupá (perímetro Corumbataí), das Áreas de Segurança Aeroportuária (conforme Resolução CONAMA no 04/1995 e Portaria n 1.141/GM5 de 1987, Ministério da Aeronáutica) e das áreas com diretrizes de uso diferenciado, estipuladas pelo Plano Diretor Municipal. Neste ponto, há que se destacar um tratamento diferenciado a ser dado para a Estação Ecológica de São Carlos, uma Unidade de Conservação de proteção integral situada no município de Brotas, na divisa com São Carlos

Cabe observar que as áreas com diretrizes de uso diferenciado conforme Plano Diretor Municipal (zona de produção agrícola multifamiliar e áreas de especial interesse histórico, turístico e paisagístico), por não constituírem objetos de restrição absoluta à implantação do empreendimento, não foram objeto específico de ponderação nesta primeira escala de abordagem. Entretanto, em função dos objetivos que justificaram sua criação e incorporação ao planejamento do município, tais áreas foram destacadas de modo a auxiliar na tomada de decisão. Da mesma forma, não foram consideradas como inaptas as áreas situadas nas zonas de segurança aeroportuária (um raio de 13 quilômetros ao redor de aeroportos), mas novamente indicadas no mapa final para auxiliar na tomada de decisão.

O resultado derivado desta primeira etapa de aproximação é apresentado na Figura 1. O produto elaborado nesta fase compreende a análise de todas as alternativas locacionais no município de São Carlos, já indicando suas diferentes classes de aptidão ambiental.

Tabela 2 - Fatores considerados para determinação da aptidão do território para localização do aterro sanitário.

\begin{tabular}{|c|c|}
\hline Primeira aproximação & Outras aproximações \\
\hline $\begin{array}{l}\text { Formações geológicas de } \\
\text { superfície }\end{array}$ & Presença de comunidades/núcleos rurais \\
\hline Tipos de solo & $\begin{array}{l}\text { Aspectos geotécnicos (hidrogeologia, } \\
\text { espessura do material inconsolidado, } \\
\text { identificação de falhas, etc.) }\end{array}$ \\
\hline Relevo & Infraestrutura (viário, energia, etc.) \\
\hline Águas superficiais & Ventos predominantes \\
\hline Áreas de vegetação nativa & Estrutura fundiária \\
\hline \multicolumn{2}{|l|}{ Áreas urbanas } \\
\hline \multicolumn{2}{|l|}{ Aeroportos/aeródromos } \\
\hline \multicolumn{2}{|l|}{$\begin{array}{l}\text { Áreas com diretrizes de uso } \\
\text { diferenciado conforme Plano } \\
\text { Diretor Municipal }\end{array}$} \\
\hline Unidades de Conservação & \\
\hline
\end{tabular}

Tabela 3 - Fatores ambientais considerados na primeira aproximação e respectivas classes de aptidão.

\begin{tabular}{|c|c|c|}
\hline Fator ambiental & & Classe de aptidão \\
\hline \multirow{4}{*}{$\begin{array}{l}\text { Formações } \\
\text { geológicas de } \\
\text { superfície }\end{array}$} & Formação Corumbataí & Alta \\
\hline & Formação Serra Geral (Derrames basálticos, diques e sills) & Média \\
\hline & Grupo Bauru e Formações Botucatu e Pirambóia & Baixa \\
\hline & Aluviões & Inapta \\
\hline \multirow{4}{*}{ Tipos de solo } & Latossolos eutroférrico, distroférrico e vermelho & Alta \\
\hline & Latossolo vermelho-amarelo; argissolos e nitossolos & Média \\
\hline & Neossolos litólico e quartzarênico & Baixa \\
\hline & Gleissolos & Inapta \\
\hline \multirow{4}{*}{ Relevo } & Declividade entre 2 e $8 \%$ & Alta \\
\hline & Declividade inferior a $2 \%$ ou entre 8 e $15 \%$ & Média \\
\hline & Declividade entre 15 e $20 \%$ & Baixa \\
\hline & Declividade superior a $20 \%$ & Inapta \\
\hline \multirow{3}{*}{$\begin{array}{l}\text { Águas } \\
\text { superficiais }\end{array}$} & $\begin{array}{l}\text { Distância superior a } 300 \text { metros em relação aos corpos d'água superficiais (rios, represas, etc.) e solos sob } \\
\text { influência do lençol freático. }\end{array}$ & Apta \\
\hline & $\begin{array}{l}\text { Distância inferior a } 300 \text { metros em relação aos corpos d'água superficiais (rios, represas, etc.) e solos sob } \\
\text { influência do lençol freático. }\end{array}$ & Inapta \\
\hline & Áreas de proteção de mananciais. & Inapta \\
\hline \multirow[b]{2}{*}{$\begin{array}{l}\text { Áreas de } \\
\text { vegetação nativa }\end{array}$} & Ausência de vegetação nativa. & Apta \\
\hline & $\begin{array}{l}\text { Presença de vegetação nativa (cerrado, vegetação de várzea, áreas em estágio clímax ou em estágios médio } \\
\text { ou avançado de regeneração de Mata Atlântica). }\end{array}$ & Inapta \\
\hline \multirow{2}{*}{ Uso do solo } & $\begin{array}{l}\text { Locais situados a distâncias superiores a } 2.000 \text { metros de áreas urbanizadas ou do perímetro urbano, } \\
\text { incluindo distritos e condomínios. }\end{array}$ & Apta \\
\hline & $\begin{array}{l}\text { Área urbanizada ou dentro do perímetro urbano e locais situados a distâncias inferiores a } 2.000 \text { metros de } \\
\text { áreas urbanizadas ou do perímetro urbano, incluindo distritos e condomínios. }\end{array}$ & Inapta \\
\hline
\end{tabular}


Como orientação para a identificação de alternativas locacionais, e ilustrando a integração de critérios técnicos aos ambientais, a projeção para o volume de resíduos gerados no município ao longo da vida útil mínima estabelecida para o empreendimento (20 anos) implica em considerar que as alternativas locacionais para o novo aterro encontram-se, preferencialmente, nas áreas de maior aptidão e com extensão contínua superior a 35 hectares. Foram identificadas 21 áreas que atendiam os critérios de primeira aproximação, estas áreas foram avaliadas in loco quanto a certas condições em que se encontravam à época, possibilitando o estabelecimento dos critérios a serem aplicados no nível seguinte de aproximação, conforme Figura 2.

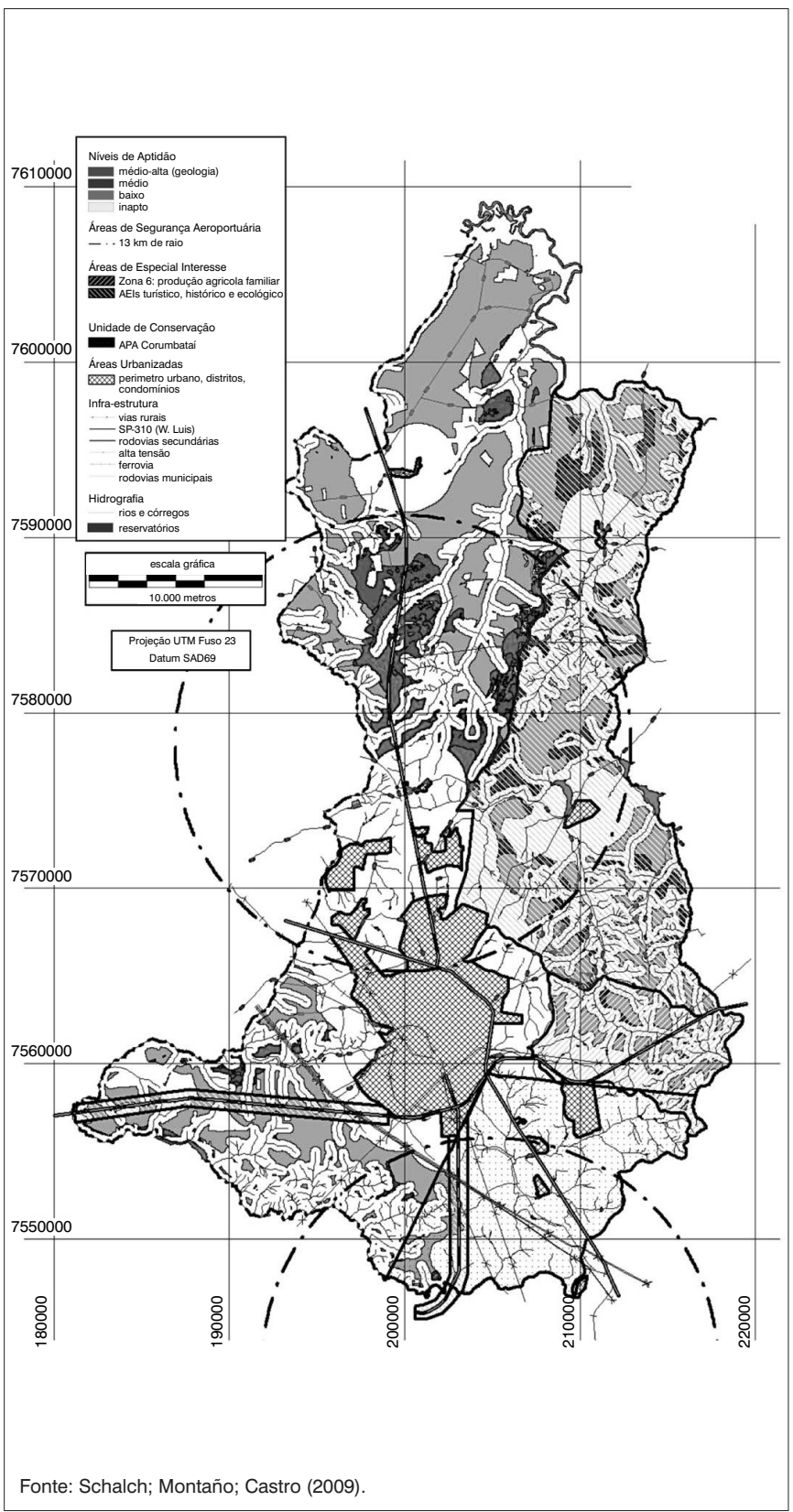

Figura 1 - Aptidão do território para implantação de aterro sanitário (primeira aproximação).

\section{Aplicação dos critérios - segunda aproximação}

Após a identificação das áreas que observaram os critérios da primeira aproximação, foram estabelecidos alguns critérios técnico-ambientais para a segunda aproximação, conforme a Tabela 4, bem como a justificativa para a sua adoção.

A avaliação destes critérios foi realizada de dois modos: por inspeção em trabalhos de campo e por meio de técnicas de geoprocessamento (avaliando-se os critérios de distância, ventos predominantes, disposição topográfica e potencial de impacto visual). Em ambos os casos, foi estabelecida uma base qualitativa de comparação para todos os critérios, à exceção da distância ao centro gerador (na Tabela 4, critério B) que foi comparado a partir de seu valor absoluto.

a) Estrutura fundiária - com base nas informações levantadas, as áreas inspecionadas a partir dos pontos 7, 8 e 11 apresentam indicativos de se localizarem sobre propriedades de porte pequeno ou médio.

b) Distância ao centro gerador - uma avaliação a partir da base cartográfica digital, considerando o acesso pelas vias existentes, indica que as áreas aptas para implantação do aterro encontram-se a distâncias que variam de 9 a 30 quilômetros da área urbana de São Carlos.

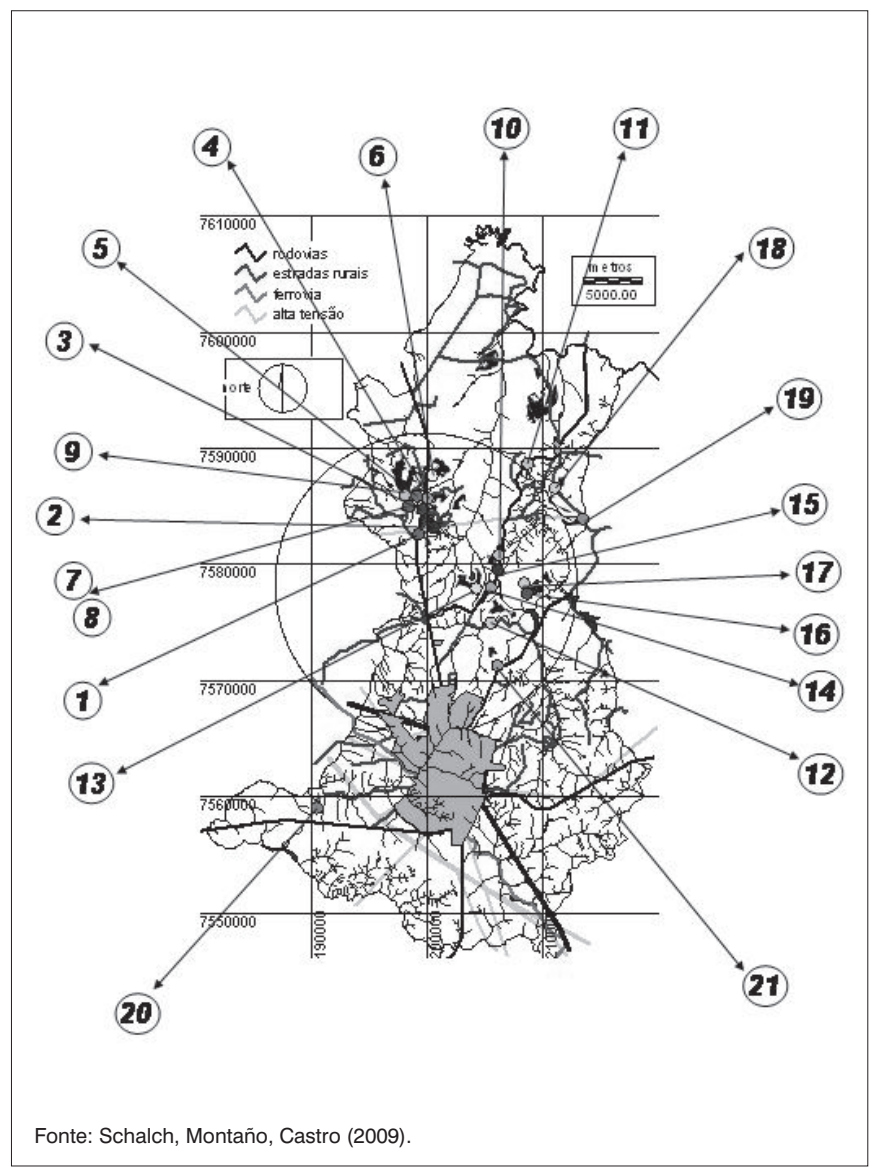

Figura 2 - Alternativas locacionais em primeira aproximação. 
Tabela 4 - Critérios estabelecidos para a seleção de alternativas locacionais.

CRITÉRIO JUSTIFICATIVA

(A) Estrutura fundiária

(B) Distância ao centro gerador

(C) Posicionamento em relação aos ventos predominantes

(D) Condições de acesso existentes

(E) Existência de habitações próximas

(F) Potencial para impacto visual
Admitindo a desapropriação de uma área de cerca de 35 hectares para a implantação do aterro sanitário, o impacto sobre a propriedade é maior sobre propriedades de pequeno porte, podendo até mesmo inviabilizar sua exploração. Nesse sentido, a preferência recai sobre áreas localizadas em grandes propriedades.

Tal característica incide diretamente sobre o risco de impacto ambiental relacionado ao transporte dos resíduos até o local de destinação final, além dos custos para sua realização.

A fim de minimizar o impacto/incômodo à população relacionada a possíveis emissões de odores do aterro, considera-se mais adequado que a área a ser utilizada para esta atividade esteja localizada de forma a evitar que núcleos habitacionais se posicionem a jusante do empreendimento e ao longo do eixo dos ventos predominantes (no caso, NE-SW).

Por conta do transporte dos resíduos até o aterro, a preferência recai sobre locais com acesso que não atravessem ou mesmo tangenciem núcleos habitacionais rurais.

Para minimizar conflitos de natureza socioambiental, a área do novo aterro deverá ser localizada sobre um local distante de habitações.

Um dos problemas relacionados à operação de um aterro sanitário, os impactos visuais foram avaliados num primeiro momento quanto à existência de locais de grande fluxo de pessoas (rodovias, sobretudo) que tenham acesso visual à área em que se localizaria o aterro. c) Posicionamento em relação aos ventos predominantes - considerando-se o eixo NE-SW verifica-se que as áreas localizadas no entorno dos pontos 10, 12, 13, 14, 15, 16, 17 e 21 encontram-se no eixo de predominância dos ventos, em direção à zona urbana de São Carlos, e bastante próximos a um distrito municipal (Água Vermelha). Cabe destacar que os pontos 11 e 18 encontram-se entre 2,5 e 3,0 km de distância de outro distrito (Santa Eudóxia), embora em posição favorável quanto ao sentido dos ventos predominantes, o que indica a necessidade de uma avaliação específica quanto a este critério.

d) Condições de acesso - uma avaliação preliminar indica que as áreas no entorno dos pontos 5, 7, 8, 9 e 17 são áreas com acesso ruim.

e) Habitações próximas - existem indicativos de que as áreas ao redor dos pontos 2, 4, 7, 8, 11 e 19 apresentam habitações em suas imediações; na área 20 foi identificada uma única habitação isolada.

f) Potencial para geração de impactos visuais - as áreas ao redor dos pontos 1, 3, 4, 5 e 6 estão no campo de visada da rodovia SP-318; as áreas ao redor dos pontos 11 e 15 estão no campo de visada da estrada municipal Abel Terrugi.

Sinteticamente, a Tabela 5 apresenta os resultados das avaliações efetuadas, com destaque aos pontos que apresentam apenas uma avaliação negativa.

Com base na Tabela 5, é possível verificar que as áreas situadas no entorno de 14 pontos apresentam apenas uma resposta negativa aos critérios avaliados. Como critérios para esta segunda aproximação, convém resgatar as restrições de caráter institucional a certas áreas do município especificamente aplicadas à implantação de aterros sanitários - em especial, a delimitação da Área de Segurança Aeroportuária,
Tabela 5 - Síntese das avaliações efetuadas.

\begin{tabular}{|c|c|c|c|c|c|c|}
\hline \multirow{2}{*}{$\begin{array}{l}\text { Ponto } \\
\text { (local) }\end{array}$} & \multicolumn{6}{|c|}{ Critérios } \\
\hline & (A) & (B) & (C) & (D) & (E) & $(F)$ \\
\hline 1 & + & $17.750 \mathrm{~m}$ & + & + & + & - \\
\hline 2 & + & $19.630 \mathrm{~m}$ & + & + & - & + \\
\hline 3 & + & $19.900 \mathrm{~m}$ & + & + & + & - \\
\hline 4 & + & $21.050 \mathrm{~m}$ & + & + & - & - \\
\hline 5 & + & $21.800 \mathrm{~m}$ & + & - & + & - \\
\hline 6 & + & $23.320 \mathrm{~m}$ & + & + & + & - \\
\hline 7 & - & $20.600 \mathrm{~m}$ & + & - & - & + \\
\hline 8 & - & $20.600 \mathrm{~m}$ & + & - & - & + \\
\hline 9 & + & $21.800 \mathrm{~m}$ & + & - & + & + \\
\hline 10 & + & $20.350 \mathrm{~m}$ & - & + & + & + \\
\hline 11 & - & $28.990 \mathrm{~m}$ & - & + & - & - \\
\hline 12 & + & $14.700 \mathrm{~m}$ & - & + & + & + \\
\hline 13 & + & $17.060 \mathrm{~m}$ & - & + & + & + \\
\hline 14 & + & $17.200 \mathrm{~m}$ & - & + & + & + \\
\hline 15 & + & $18.800 \mathrm{~m}$ & - & + & + & - \\
\hline 16 & + & $21.550 \mathrm{~m}$ & - & + & + & + \\
\hline 17 & + & $22.800 \mathrm{~m}$ & - & - & + & + \\
\hline 18 & + & $29.200 \mathrm{~m}$ & - & + & + & + \\
\hline 19 & + & $25.500 \mathrm{~m}$ & + & + & - & + \\
\hline 20 & + & $13.900 \mathrm{~m}$ & + & + & + & - \\
\hline 21 & + & $8.600 \mathrm{~m}$ & - & + & + & + \\
\hline
\end{tabular}

Em destaque, as alternativas locacionais que se mostram mais favoráveis ao empreendimento, com apenas um aspecto avaliado como negativo.

além da Zona de Produção Agrícola Familiar (conforme Plano Diretor Municipal), e da Área de Especial Interesse turístico, histórico e ecológico (conforme Plano Diretor). A Estação Ecológica de São Carlos poderia implicar em algum tipo de restrição formal ao empreendimento, no entanto não conta com um Plano de Manejo elaborado e aprovado que viesse a delimitar sua zona de amortecimento e as restrições aplicáveis, sendo o empreendimento passível de licenciamento mediante manifestação do gestor desta UC. 
Tabela 6 - Tipo de ressalva apresentada para os pontos considerados potencialmente viáveis à implantação do aterro sanitário.

\begin{tabular}{|c|c|c|}
\hline Pontos & Distância (m) & Ressalvas \\
\hline 9 & 21.800 & Condições de acesso, trajeto, ASA. \\
\hline 16 & 21.550 & $\begin{array}{l}\text { Ventos predominantes, trajeto, área de } \\
\text { interesse turístico, ASA. }\end{array}$ \\
\hline 18 & 29.200 & $\begin{array}{l}\text { Condições de acesso, trajeto por município } \\
\text { vizinho, distância ao centro gerador, ventos } \\
\text { predominantes. }\end{array}$ \\
\hline 19 & 25.500 & $\begin{array}{l}\text { Indicativo de habitações próximas, condições } \\
\text { de acesso, trajeto por município vizinho, } \\
\text { distância ao centro gerador. }\end{array}$ \\
\hline 20 & 13.900 & $\begin{array}{l}\text { Habitação isolada e proximidade com Unidade } \\
\text { de Conservação. }\end{array}$ \\
\hline 21 & 8.600 & $\begin{array}{l}\text { Ventos predominantes, ASA, área } \\
\text { pertencente à EMBRAPA (dificuldades para } \\
\text { desapropriação) e já havia indicação de uso. }\end{array}$ \\
\hline
\end{tabular}

Com relação à Área de Segurança Aeroportuária, dos 14 pontos indicados anteriormente, apenas os pontos 18, 19 e 20 não se encontram inseridos nessa área.

Esta segunda etapa de aproximação requer trabalhos de campo para levantamento de informações específicas de interesse. Neste momento, procurou-se avaliar as condições que se apresentariam para a viabilização da alternativa locacional, sobretudo em termos da sua viabilização política e institucional - novamente, considerando o efeito NIMBY como bastante significativo para esta tipologia de empreendimento, assumem relevância os critérios relacionados a efeitos negativos sobre a vizinhança (incômodos no transporte dos resíduos, odor, impactos sobre outras atividades de interesse, etc.) e aspectos institucionais como dificuldades para desapropriação da gleba e interferências em municípios vizinhos.

Sendo assim, para uma investigação sobre as áreas e em seu entorno, procurou-se identificar a existência de alguma situação que indicasse um impedimento ou uma restrição significativa para a acomodação do aterro sanitário, a saber:

- Existência de habitações (mesmo que isoladas) ou pequenas propriedades (chácaras, sítios, empreendimentos comerciais, etc.) nas áreas indicadas ou em seu entorno imediato, incluindo uma avaliação sobre o trajeto mais provável dos caminhões durante o transporte dos resíduos;

- Existência de algum atributo ambiental não contemplado nas etapas anteriores, devido à escala utilizada - por exemplo, a existência de nascentes e olhos d'água - mantendo-se os critérios ambientais estabelecidos anteriormente;

- A verificação de uma situação divergente da situação idealizada pela sobreposição das informações - por exemplo, uma mancha de solos com características diferenciadas do tipo de solo que se esperava encontrar (o que indicaria uma divergência entre a informação mapeada e a informação real) ou uma conformação topográfica divergente quanto aos critérios ambientais.

A Tabela 6 apresenta o tipo de ressalva apresentada por cada um destes pontos, identificadas ao longo desta segunda etapa de aproximação.

Após esta etapa de trabalhos de campo, foram destacadas as áreas 09, 16 e 20 como as alternativas locacionais a serem investigadas em detalhe quanto à viabilidade ambiental do empreendimento e sua localização e apresentadas na terceira aproximação.

\section{Aplicação dos critérios - terceira aproximação}

A terceira aproximação envolve o levantamento de informações específicas sobre as condições geológico-geotécnicas, essenciais para a verificação do desempenho ambiental e operacional do empreendimento. Por meio de sondagens a trado foram identificadas, em primeira instância, as características gerais para as alternativas locacionais (perfil de solo e profundidade do lençol freático). Em seguida, foi realizada uma campanha de sondagens para o detalhamento de tais características.

Dentre os resultados da sondagem, a área 9 foi a que apresentou a menor aptidão com relação às características geotécnicas, tendo em vista a ocorrência de areia fina pouco argilosa nos três furos realizados. Os resultados das sondagens realizadas nas áreas 16 e 20 descrevem um solo com argila muito siltosa, pouco arenosa, considerado apropriado para a implantação de aterros sanitários.

O aspecto hidrogeológico indicou a área 20 como um diferencial importante após nova campanha de sondagens e verificação in loco das características favoráveis da referida área. Assim, após um detalhado estudo de localização, a área mais indicada contemplando aspectos econômicos, sociais e ambientais foi a área 20, que foi indicada para a implantação do novo aterro e a ser detalhada para avaliação final da viabilidade ambiental.

\section{Discussão e conclusão}

Tradicionalmente, o processo de escolha de área para implantação de aterros é focado em aspectos técnicos e econômicos, negligenciando outros elementos ambientais e sociais. Contudo, este tipo de empreendimento é naturalmente associado ao efeito NIMBY, o que conduz a soluções nem sempre satisfatórias do ponto de vista social e ambiental e acarreta em um processo de avaliação e licenciamento ambiental conturbado (PFEIFFER, 2001; HARTMAN; GOLTZ, 2002).

Estudos de alternativas locacionais implicamna integração de requisitos ambientais aos requisitos de projeto, rompendo de certa forma com as tradicionais análises custo-benefício aplicadas a projetos 
de engenharia, que têm dificuldades para tratar de requisitos ambientais do mesmo modo que os demais requisitos de desempenho para os projetos analisados.

A metodologia apresentada permite integrar os aspectos ambientais, sociais e econômicos a partir dos critérios estabelecidos com a participação da sociedade. As aproximações sucessivas ofereceram condições bastante satisfatórias para o desenvolvimento do projeto (técnico) do novo aterro e para a integração/adaptação de requisitos ambientais e, assim, antecipar os impactos significativos e estabelecer requisitos de desempenho ambiental a serem incorporados pelo projeto do empreendimento.
O processo de identificação de alternativas para o desenvolvimento de atividades sobre o território foi devidamente amparado por informações que permitiram a incorporação da sustentabilidade. Com isso, foi possível montar um cenário em que o poder público e a sociedade puderamtomar a decisão com a devida adequação ambiental.

O resultado obtido propiciou a minimização de medidas de mitigação e compensação, o aumento da segurança do empreendimento com a diminuição de riscos no seu gerenciamento, a facilitação dos processos de elaboração dos estudos ambientais, principalmente nas etapas de diagnósticos e avaliações de impacto preliminares e, posteriormente, a aprovação do empreendimento.

\section{Referências}

ABNT/NBR 13.896/1997. (1997) Aterros de resíduos não perigosos Critérios para projeto, implantação e operação - Procedimentos. São Paulo: Associação Brasileira de Normas Técnicas.

BASAGAOGLU, H.; CELENK, E.; MARIÑO, M.A.; USUL, N. (1997) Selection of waste disposal sites using GIS. Journal of the American Water Resources Association, v. 33, n. 2, p. 455-64.

BASÍLIO, J.A.F. (2001) Procedimentos para seleção de áreas para aterros sanitários a partir de cartas geotécnicas: aplicação na folha de Campinas (SP). Dissertação (Mestrado). Rio Claro: Universidade Estadual Paulista Júlio de Mesquita Filho.

BRASIL. (2002) Ministério do Meio Ambiente. Fomento a projetos de ordenamento da coleta e disposição final adequada de resíduos sólidos: orientações básicas para solicitação de recursos. Brasília: Ministério do Meio Ambiente.

CHARNPRATHEEP, K.; ZHOU, Q.; GARNER, B. (1997) Preliminary landfill site screening using fuzzy geographical information systems. Waste Management \& Research, v.15, n.2, p. 197-215

DÖRHÖFER, G.; SIEBERT, H. (1998) The search for landfill sites - requirements and implementation in Lower Saxony, Germany. Environmental Geology, v. 35, n. 1, p. 55-65.

DORN, M.; TANTIWANIT, W. (2001) New methods for searching for waste disposal sites in the Chiang Mai-Lamphun Basin, northern Thailand. Environmental Geology, v. 40, n. 4-5, p. 507-17.

FREMPONG, E.M. (1999) Engineering geological assessment of a proposed waste disposal site in coastal southwestern Ghana. Environmental Geology, v. 37, n. 3, p. 255-60.

HARTMAN, D.H.; GOLTZ, M.N. (2002) Application of the analytic hierarchy process to select characterization and risk-based decisionmaking and management methods for hazardous waste sites. Environmental Engineering Policy, v. 3, n. 1-2, p. 1-7.

KAO, J.J.; LIN, H.Y. (1996) Multifactor spatial analysis for landfill siting. Journal of Environmental Engineering, v. 122, n. 10, p. 902-8.
KARTHIKEYAN, K.G.; ELLIOTT, H.A.;BRANDT, R.C. (1996) Siting monofills for residuals using GIS. Journal American Water Works Association, v. 88, n. 2, p. 68-75.

LEAO, S.; BISHOP, I.; EVANS, D. (2001) Assessing the demand of solid waste disposal in urban region by urban dynamics modelling in a GIS environment. Resources, Conservation and Recycling, v. 33, n. 4 , p. 289-313.

MAHLER, C.F.; LIMA, G.S. (2003) Applying value analysis and fuzzy logic to select areas for installing waste fills. Environmental Monitoring and Assessment, v. 84, n. 1-2, p. 129-40.

MARQUES, G.N. (2002) Seleção de áreas para aterros sanitários baseada em mapeamento geotécnico e analytic hierarchy process AHP. Dissertação (Mestrado). São Carlos: Universidade de São Paulo.

MCHARG, I.L. (1969) Design with nature. 1992 edition. New York: John Wiley and Sons.

MURO, M.D. (2000) Carta de zoneamento para seleção de áreas frente à instalação de aterros sanitários no Município de São Carlos - SP Escala 1:50.000. Dissertação (Mestrado). São Carlos: Universidade de São Paulo.

OLIVEIRA, I.S.D.; MONTAÑO, M.; SOUZA, M.P. (2009) Avaliação ambiental estratégica. São Carlos: Suprema.

PEARCE, D.; TURNER, R.K. (1991) Economics of natural resources and the environment .London: John Hopkins University Press.

PFEIFFER, S.C. (2001) Subsídios para a ponderação de fatores ambientais na localização de aterros de resíduos sólidos utilizando o sistema de informações geográficas. Tese (Doutorado).São Carlos: Universidade de São Paulo.

RYDIN, Y. (1998) Land use planning and environmental capacity: reassessing the use regulatory policy tools to achieve sustainable development. Journal of Environmental Planning and Management, v. 41, n. 6, p. 749-65. 
SÃO PAULO (Estado). SECRETARIA DE MEIO AMBIENTE. (2005) Procedimentos para implantação de aterro sanitário em valas. Disponível em: <http://www.ambiente.sp.gov.br/valas/proced_implantacao/proc_ implant.pdf >. Acesso em: 15 nov. 2007.

SCHALCH, V.; MONTAÑO, M.; CASTRO, M.C.A.A. (coord). (2009) Estudo de impacto ambiental para implantação do novo aterro sanitário no município de São Carlos (SP). São Carlos: Fundação para o Incremento da Pesquisa e do Aperfeiçoamento Industrial.

SENER, B.; SÜZEN, M.L.; DOYURAN, V. (2005) Landfill site selection by using geographical information systems. Environmental Geology, v. 49, n. 3, p. 376-88.

SIDDIQUI, M.Z.; EVERETT, J.W.; VIEUX, B.E. (1996) Landfill siting using geographical information systems: a demonstration. Journal of Environmental Engineering, v. 122, n. 6, p. 515-23.

SOUZA, F.C.B. (1999) Sistema de apoio à decisão em ambiente espacial aplicado em um estudo de caso de avaliação de áreas destinadas para disposição de resíduos sólidos na região metropolitana de Porto Alegre. Tese (Doutorado). Florianópolis: Universidade Federal de Santa
Catarina. Disponível em: < http://www.eps.ufsc.br/teses99/souza/index. html>. Acesso em: 16 mar. 2007.

SOUZA, M.P. (2000) Instrumentos de gestão ambiental: fundamentos e prática. São Carlos: Riani Costa.

THERIVEL, R. (2010) Strategic environmental assessment in action. $2^{\text {nd }}$ ed. London: Routledge.

TSUHAKO, E.M. (2004) Seleção preliminar de locais potenciais à instalação de aterros sanitários na sub-bacia da represa de Itupararanga (bacia dos rios Sorocaba e Médio Tietê). Dissertação (Mestrado). São Carlos: Universidade de São Paulo.

VAN BELLEN, H.M. (2007) Indicadores de sustentabilidade: uma análise comparativa. 2 ed. Rio de Janeiro: Fundação GetúlioVargas.

ZUQUETTE, L.V.; PEJON, O.J.; SINELLI, O.; GANDOLFI, (1994) $\mathrm{N}$. Methodology of specific engineering geological mapping for selection of sites for waste disposal. In: $7^{\text {th }}$ International Congress of the International Association of Engineering Geology. Proceedings. Lisboa, v. 4, p. 2481-90. 